\title{
AVALIAÇÃO DA ATIVIDADE ANTIOXIDANTE E CITOTÓXICA DO ÓLEO DA SEMENTE DE PEQUI (Caryocar coriaceum Wittm., ARECACEAE)
}

\author{
Paloma Maria Da Silva ${ }^{1}$, Matheus Ranieli Calado Lima ${ }^{1 *}$, João Victor de Oliveira Alves ${ }^{1}$, Graziela Claudia da Silva ${ }^{1}$, \\ Marcia Vanusa da Silva ${ }^{1}$, Alexandre Gomes da Silva ${ }^{1}$, Maria Tereza dos Santos Correia ${ }^{1}$ \\ 1Laboratório de Produtos Naturais, Departamento de Bioquímica, CB-UFPE ${ }^{1}$ \\ *matheuscaladolima@gmail.com
}

\section{INTRODUÇÃO}

0 uso de plantas medicinais para tratamento, cura e prevenção de doenças tem sido descrito por muitos povos desde os tempos mais remotos. Devido a esse uso, surgiram interesses comerciais e cientí ficos e, por isso, tornou-se necessária a avaliação da eficácia e segurança dessas plantas. Os óleos vegetais naturais apresentam inúmeras vantagens para uso terapêutico, como baixa toxicidade, elevada biodegradabilidade que é a capacidade que algumas substâ ncias químicas têm de poderem ser usadas como substratos por microrganismos e são renováveis quanto à disponibilidade em relaç ão aos derivados de petróleo que são finitos. Dentre as espécies produtoras de óleos vegetais destacam-se as espécies do gênero Caryocar. No Brasil Caryocar brasiliense, C. villosum, C. coriaceum, C. cuneatum e C. glabrum são as espécies mais importantes. Caryocar coriaceum Wittm é encontrada na parte mais setentrional do Nordeste, exercendo importante papel socioeconômico na Chapada do Araripe. Seu fruto é usado como alimento e na medicina popular como anti-inflamatório e cicatrizante. Devido a toda versatilidade dos óleos vegetais, o trabalho tem como principais objetivos avaliar os efeitos antioxidante e citotóxico de óleos vegetais da semente de Pequi (Caryocar coriaceum).

\section{MATERIAIS E MÉTODOS}

Os frutos de $C$. coriaceum foram coletados de diferentes espécimes na Floresta Nacional do Araripe-Apodi (Ceará, Brasil). O material vegetal foi acondicionado em sacos de papel, devidamente etiquetados e levados ao Laboratório de Produtos Naturais, do Departamento de Bioquímica, do Centro de Biociências, da Universidade Federal de Pernambuco. Os frutos foram despolpados e as sementes foram lavadas com água destilada e postas para secar em estufa de circulação forçada de ar, à $45^{\circ} \mathrm{C}$, por $72 \mathrm{~h}$. Apó $\mathrm{s}$ secos foram triturados em moinhos para a produção de um pó. 0 material vegetal seco e triturado foi submetido à extração com hexano em aparato Soxhlet, por 8 h. Após a extração, o solvente foi removido em pressão reduzida, à $50{ }^{\circ} \mathrm{C}$, em evaporador rotató rio

A atividade sequestradora de radical livre foi medida em termos de doação de hidrogênio usando o radical estável 2,2-difenil1picrilhidrazil (DPPH) (BLOIS, 1958). A solução de DPPH $(250 \mu \mathrm{L})$ foi misturada em $40 \mu \mathrm{L}$ de diferentes concentrações dos óleos (3,12 a $200 \mu \mathrm{L} / \mathrm{mL}$ ),. Absorbância (Abs) foi medida após 25 min em 517nm. Trolox (análogo da vitamina $\mathrm{E}$, solúvel em água), Ácido Gálico e BHT foram usados como composto de referência e o controle foi o DPPH adicionado a $40 \mu \mathrm{L}$ de DMSO a $20 \%$ (solvente utilizado para diluir as amostras). A eliminação dos radicais de DPPH foi calculada da seguinte forma:

$$
\text { Eliminação }[\mathrm{DPPH}](\%)=\frac{(\text { Abs amostra }- \text { Abs controle })}{\text { Abs controle }} \times 100
$$

Figura 1. Fórmula para cálculo da atividade de sequestro do radical DPPH

A atividade hemolítica foi realizada seguindo a metodologia de Harris \& Phoenix (1997). Onde uma alíquota de $1,1 \mathrm{~mL}$ de suspensã o de eritrócitos foi misturada a $0,4 \mathrm{~mL}$ das amostras em diferentes concentrações $(125-1000 \mu \mathrm{g} / \mathrm{mL})$. O controle negativo e controle positivo receberam $0,4 \mathrm{~mL}$ de tampão fosfato-salina e de Triton $\mathrm{X}$ 100 a $1 \%(\mathrm{v} / \mathrm{v})$, respectivamente. Após $60 \mathrm{~min}$ de incubação em temperatura ambiente $\left(27^{\circ} \mathrm{C}\right)$, as células foram centrifugadas e 0 sobrenadante foi usado para medir a absorbância da hemoglobina liberada a $540 \mathrm{~nm}$. O valor médio foi calculado a partir dos ensaios em quadruplicata. A atividade hemolítica foi expressa em relação à ação do Triton X-100 e calculada pela seguinte fórmula:

Sendo, Aa - absorbância da amostra, Ab - absorbância do controle negativo (tampão fosfato-Salina) e Ac - absorbância do controle positivo (Triton X-100).

$$
\text { Atividade hemolítica }(\%)=\frac{[(\mathrm{Aa}-\mathrm{Ab}) .100]}{(\mathrm{Ac}-\mathrm{Ab})}
$$

Figura 2. Fórmula para cálculo da atividade hemolítica

\section{RESULTADOS E DISCUSSÃO}

Em relação a avaliação da atividade antioxidante pelo sequestro de radicais livres pelo método do DPPH, observou-se que o percentual de sequestro para o óleo da semente variou de 30 a 6,3\%. 0 mesmo realizou o teste com o método de peroxidação lipídica para o óleo e afim de se obter outros resultados, que em comparação com o método de DPPH mostrou melhor resultado para o óleo que foi de 44,3 comparando com o ácido gálico descrito no gráfico 1 .

De acordo com Castelo-Branco e Torres (2011), a determinação da capacidade antioxidante em óleos é um desafio analítico, pois a maioria dos métodos foi desenvolvida para a análise de compostos hidrofílicos em amostras hidrofílicas. Os óleos vegetais são hidrofó bicos e não se misturam ao meio aquoso, peculiar aos ensaios de capacidade antioxidante. Consequentemente, a turbidez da 
amostra prejudica a determinação e dessa forma, são necessárias adaptações nos ensaios para amostras cujos componentes majoritá rios sejam lipídeos. Entretanto, esta adaptação é difícil tornando os resultados de difícil interpretação e pouco informativos. Mesmo com o número crescente de estudos para atividade antioxidante de óleos ainda não há consenso sobre a adaptação dos ensaios disponí veis, podendo justificar os resultados da baixa atividade dos óleos estudados.

Gráfico 1. Atividade Antioxidante do óleo da semente do Pequi em comparação com o á cido gálico pelo método do DPPH

Atividade Antioxidante por DPPH

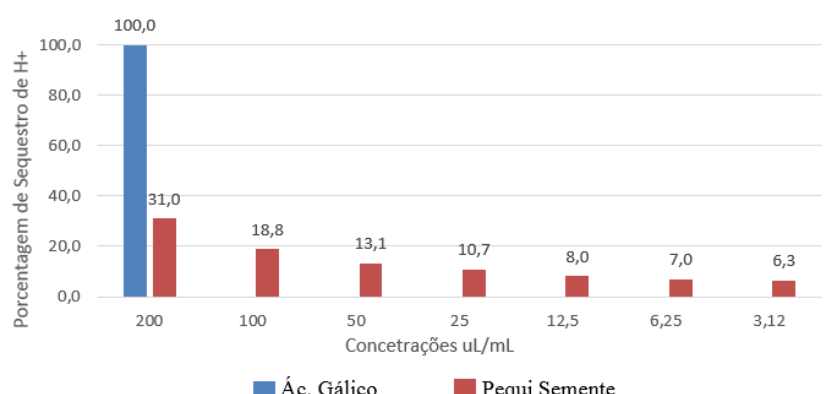

0 teste mostrou qualitativamente que o óleo do pequi não apresentou ação hemolítica visto que não foi observada formação de hemólise em nenhuma das concentrações do óleo testado, permanecendo límpida a solução de soro fisiológico após a centrifugação, ou seja, as hemácias permaneceram íntegras no fundo dos tubos, com a formação de um precipitado, sem que tenha havido a lise das células. Ao contrário do controle positivo (Triton X-100). As plantas contêm princípios ativos responsáveis pelas propriedades terapêuticas a elas atribuídas, mas também, por reações adversas que podem aparecer em decorrência de uso indevido ou contado direto com a mesma. A ação tóxica de alguns metabólitos secundários já é bem evidenciada. DINIZ et al., 2006.

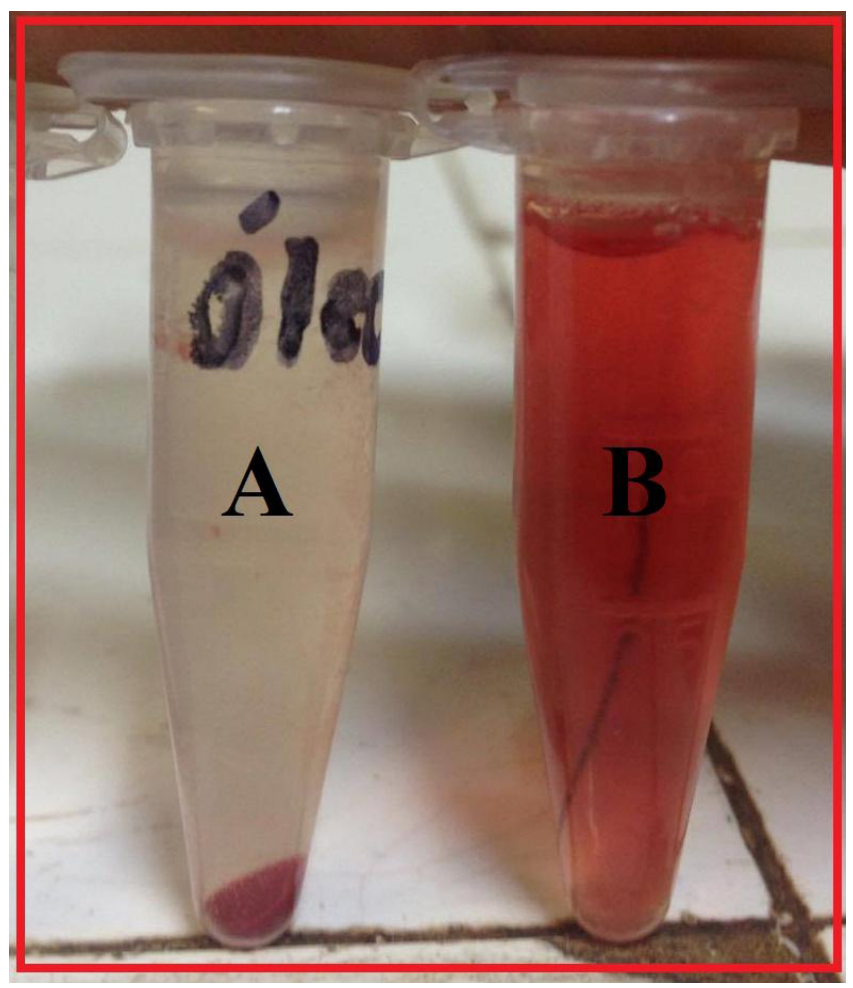

Figura 3. Teste hemolítico feito com o óleo do pequi puro (A), e Triton $X-100$, frente a eritrócitos (B).

\section{CONCLUSÕES}

O óleo foi eficientemente extraído apresentou um resultado muito significativo para o teste de toxicidade frente a eritrócitos. Além de exprimir uma relevante atividade antioxidante pelo método de sequestro de radicais livres (DPPH) que variou de 30 a $6,3 \%$.

\section{REFERÊNCIAS}

BLOIS, Marsden S. Antioxidant Determinations by the Use of a Stable Free Radical. Nature, v. 181, n. 4617, p. 1199-1200, 1958. HARRIS, F.; PHOENIX, D. A. An investigation into the ability of C. terminal homologues of Escherichia coli low molecular mass penicillin-binding proteins 4,5 and 6 to undergo membrane interaction. Biochimie, v. 79, n. 4, p. 171-174, 1997.

CASTELO-BRANCO, Vanessa Naciuk; TORRES, Alexandre Guedes. Capacidade antioxidante total de óleos vegetais comestíveis: determinantes químicos e sua relação com a qualidade dos óleos. Revista de Nutrição, v. 24, n. 1, p. 173-187, 2011.

DINIZ, LÚCIO RICARDO LEITE. Efeito das saponinas triterpênicas isoladas de raízes da Ampelozizyphus amazonicus Ducke sobre a função renal. Dissertação de Mestrado, Curso de Pós-Graduação em Ciências Biológicas, UFMG. 2006 